\title{
SIRT3 participates in glucose metabolism interruption and apoptosis induced by BH3 mimetic S1 in ovarian cancer cells
}

\author{
XI-YAN XIANG $^{1}$, JIN-SONG KANG ${ }^{1}$, XIAO-CHUN YANG ${ }^{2}$, JING SU ${ }^{1}$, YAO WU ${ }^{1}$, XIAO-YU YAN ${ }^{1}$, \\ YA-NAN XUE ${ }^{1}$, YE XU $^{3}$, YU-HE LIU ${ }^{4}$, CHUN-YAN YU ${ }^{4}$, ZHI-CHAO ZHANG $^{5}$ and LIAN-KUN SUN ${ }^{1}$ \\ ${ }^{1}$ Department of Pathophysiology, Basic College of Medicine, Jilin University, Changchun, Jilin 130021; \\ ${ }^{2}$ Centre of Nephrology and Urology, Shenzhen University Health Science Centre, Shenzhen, Guangdong 518060; \\ ${ }^{3}$ Medical Research Laboratory, Jilin Medical College; ${ }^{4}$ Department of Pathology, Basic Medical College, \\ BeiHua University, Jilin City, Jilin 132013; ${ }^{5}$ State Key Laboratory of Fine Chemicals, School of Chemistry, \\ Dalian University of Technology, Dalian, Liaoning 116012, P.R. China
}

Received February 23, 2016; Accepted April 19, 2016

DOI: 10.3892/ijo.2016.3552

\begin{abstract}
The Bcl-2 antiapoptotic proteins are important cancer therapy targets; however, their role in cancer cell metabolism remains unclear. We found that the BH3-only protein mimetic S1, a novel pan Bcl-2 inhibitor, simultaneously interrupted glucose metabolism and induced apoptosis in human SKOV3 ovarian cancer cells, which was related to the activation of SIRT3, a stress-responsive deacetylase. S1 interrupted the cellular glucose metabolism mainly through causing damage to mitochondrial respiration and inhibiting glycolysis. Moreover, S1 upregulated the gene and protein expression of SIRT3, and induced the translocation of SIRT3 from the nucleus to mitochondria. SIRT3 silencing reversed the effects of $\mathrm{S} 1$ on glucose metabolism and apoptosis through increasing the level of HK-II localized to the mitochondria, while a combination of the glycolysis inhibitor 2-DG and S1 intensified the cytotoxicity through further upregulation of SIRT3 expression. This study underscores an essential role of SIRT3 in the antitumor effect of Bcl-2 inhibitors in human ovarian cancer through regulating both metabolism and apoptosis. The manipulation of Bcl-2 inhibitors combined with the use of classic glycolysis inhibitors may be rational strategies to improve ovarian cancer therapy.
\end{abstract}

Correspondence to: Dr Lian-Kun Sun, Department of Pathophysiology, Basic College of Medicine, Jilin University, 126 Xinmin Street, Changchun, Jilin 130021, P.R. China

E-mail: sunlk@jlu.edu.cn

Abbreviations: SIRT3, Sirtuin-3; 2-DG, 2-deoxy-D-glucose; BH3, Bcl-2 homology domain 3; Oba, obatoclax mesylate; OCR, oxygen consumption rate; ECAR, extracellular acidification rates; TCA, tricarboxylic acid cycle

Key words: SIRT3, BH3 mimetic, glucose metabolism, apoptosis, ovarian cancer

\section{Introduction}

The overexpression of anti-apoptotic B-cell lymphoma 2 (Bcl-2) protein members such as Bcl-2/Bcl-xL/Mcl-1 frequently occurs in human cancers and is closely associated with cancer development and resistance to chemotherapies (1,2). By competing with anti-apoptotic Bcl-2 proteins, Bcl-2 homology domain 3 (BH3) mimetics induce cell death in a wide range of cancer cell lines. They have therefore been used as novel cancer therapy tools that target the functional $\mathrm{BH} 3$ binding groove of anti-apoptotic members of the Bcl-2 family (3). Recent studies suggest that as well as regulating apoptosis, $\mathrm{Bcl}-2$ is also involved in cancer cell metabolism $(4,5)$. For example, inhibiting Bcl-2 by the BH3 mimetic ABT-737 reduces mitochondrial oxidative phosphorylation in primitive leukemia cells (6). Moreover, Bcl-2 overexpression prevents the brain mitochondrial respiratory dysfunction induced by glutathione depletion (7). These observations imply that the regulation of cancer metabolism may be intertwined in the antitumor effect of Bcl-2 inhibitors.

Aerobic glycolysis is a key hallmark of many cancers including ovarian cancer (8), which is characterized by enhanced glucose uptake and lactate secretion, and is abnormally dependent on glycolysis for ATP production even in the presence of oxygen (9). This metabolic phenotype with a high glucose dependence and increased glucose metabolism may facilitate the proliferation of cancer cells and enable them to evade apoptosis $(10,11)$. While investigating cell death, mitochondria were shown to be under extensive metabolic control, and appear to determine whether cells respond to stress in an adaptive or suicidal way (12). Recently, the manipulation of metabolic derangement through inhibiting glycolysis and targeting mitochondrial apoptotic machinery were proposed as strategies to improve ovarian cancer therapy (13). However, the effect of Bcl-2 inhibitors on ovarian cancer cell metabolism remains unclear.

SIRT3 is a member of the sirtuin family of NAD-dependent deacetylases, which preferentially localizes to mitochondria (14). Through the deacetylation of target enzymes, SIRT3 is involved in processes of energy metabolism, including the 
respiratory chain, tricarboxylic acid cycle, fatty acid oxidation, and ketogenesis (15). Moreover, SIRT3 was recently suggested to mediate metabolic reprogramming by destabilizing hypoxia-inducible factor $1-\alpha$, a transcription factor that controls glycolytic gene expression (16). Under basal (non-stress) conditions, SIRT3 was also found to be required for apoptosis induced by the selective silencing of Bcl-2 in HCT116 human epithelial cancer cells (17). These findings imply that SIRT3 serves as an important therapeutic target involved in both cancer metabolism and apoptosis.

We previously found that $\mathrm{S} 1$, a novel pan-BH3 mimetic targeting both Bcl-2 and Mcl-1, may inhibit cancer cell growth and induce apoptosis through mitochondrial pathways and endoplasmic reticulum stress-mediated pathways (18). This study aimed to determine whether $\mathrm{S} 1$ exerts anticancer roles in SKOV3 ovarian carcinoma cells through regulating glucose metabolism. Here we found that $\mathrm{S} 1$ induces cell apoptosis and interrupts glucose metabolism in human ovarian cancer cells, partially through the activation of SIRT3. A combination of 2-DG and S1 further promotes the activation of apoptosis through enhancing the expression of SIRT3. Therefore, we proposed that a novel strategy for tumor therapy could exploit the role of SIRT3 to enhance the antitumor effect of BH3 mimetics, and glycolysis should be also considered as a potential target for the improvement of S1 efficacy.

\section{Materials and methods}

Reagents and antibodies. S1 was synthesized as previously reported (19) and dissolved in dimethyl sulfoxide (DMSO). The Bcl-2 inhibitors ABT-737, ABT-199, and obatoclax mesylate (Oba) were purchased from ApexBio (Boston, MA, USA). The glycolysis inhibitor 2-DG was purchased from Santa Cruz Biotechnology (Santa Cruz, CA, USA). Hoechst 33342, 3-(4,5-dimethylthiazol-2-yl)-2,5-diphenyltetrazolium bromide (MTT), and fetal bovine serum (FBS) were purchased from Sigma (St. Louis, MO, USA). Anti-SIRT3, anti-Mcl-1, antiBcl-2, anti-lamin A/C, anti-Cox IV, anti-Tom20, anti-caspase-3, anti-PARP and anti- $\beta$-actin antibodies were purchased from Santa Cruz Biotechnology.

Cell culture. Human ovarian carcinoma cells (SKOV3 cells) were purchased from American Tissue Culture Collection (Rockville, MD, USA) and cultured in RPMI-1640 medium supplemented with $10 \% \mathrm{FBS}, 100 \mathrm{U} / \mathrm{ml}$ penicillin, and $100 \mathrm{mg} / \mathrm{ml}$ streptomycin (complete medium), and were grown in a humidified cell culture incubator equilibrated with $95 \%$ air and $5 \% \mathrm{CO}_{2}$ at $37^{\circ} \mathrm{C}$.

Cell viability assays. Cells were seeded in 96-well plates at a density of $1 \times 10^{4}$ cells/well in $200 \mu \mathrm{l}$ of complete medium at $37^{\circ} \mathrm{C}$ with $5 \% \mathrm{CO}_{2}$. A total of $10 \mu \mathrm{l}$ of $10 \mathrm{mg} / \mathrm{ml}$ MTT reagent in phosphate-buffered saline was added to each well and incubated for $4 \mathrm{~h}$, after which any formazan crystals that formed were dissolved in $150 \mu \mathrm{l}$ DMSO. Absorbance was recorded at a wavelength of $490 \mathrm{~nm}$. The treatment was repeated in six separate wells.

Mouse experiments. All animal manipulations were performed in accordance with institutional guidelines under approved protocols. Six-week-old female athymic BALB/c nude mice were purchased from the Animal Experimental Center (Beijing, China). SKOV3 ovarian cancer cells ( $2 \times 10^{6}$ cells), were s.c. implanted into into the upper flank. Seven days after tumor cell injection, the nude mice were randomized into 2 groups of 5 mice per group: vehicle (control) and S1 $(6 \mathrm{mg} / \mathrm{kg})$. The groups of mice were intraperitoneally administered with $0.2 \mathrm{ml}$ of vehicle (DMSO in PBS, control group) or $\mathrm{S} 1$ in $0.2 \mathrm{ml}$ of vehicle every 2 days. The body weights and tumor volumes of the control and drug-treated mice were recorded prior to the start of the experiment. Tumor volume was monitored by using external caliper measurement and calculated according to the formula tumor volume (in millimeters cubed $)=\mathrm{Dx} \mathrm{d} / 2$, where $\mathrm{D}$ and $\mathrm{d}$ are the longest and shortest diameters, respectively. The mice in both the control and S1-treated groups were sacrificed at 21 days after the tumor cell injection. Tumors from each mouse treated with vehicle or S1 were carefully dissected out at the time of sacrifice, weighed, and photographed for graphical representation.

Apoptosis analysis by Hoechst 33258 staining. Apoptotic morphological alterations in nuclear chromatin were detected by Hoechst 33258 staining. Briefly, SKOV3 cells were cultured in 24-well plates and treated as indicated for $24 \mathrm{~h}$. Cells were washed with ice-cold PBS and fixed with $4 \%$ (w/v) paraformaldehyde overnight. The plates were then incubated with $10 \mathrm{M}$ Hoechst 33258 staining solution for $10 \mathrm{~min}$. The cells were visualized under a fluorescence microscope (IX-71, Olympus).

Western blot analysis. Briefly, after quantitating protein in each sample with the Bio-Rad protein reagent (Bio-Rad Laboratories, Hercules, CA, USA), (40 $\mu \mathrm{g}$ protein per well) were separated by SDS-PAGE and transferred onto an Immun-Blot PVDF membrane (Bio-Rad Laboratories). After blocked in Tris-buffered saline containing 5\% (w/v) non-fat dry milk at room temperature for $1 \mathrm{~h}$, the membranes were incubated with specific primary antibodies overnight at $4^{\circ} \mathrm{C}$. After washed with PBS-Tween-20, membranes were incubated with horseradish-peroxidase-conjugated secondary antibodies (Santa Cruz Biotechnology) at room temperature for $1 \mathrm{~h}$. Membranes were then incubated in ECL reagents and images captured by Syngene Bio Imaging (Synoptics, Cambridge, UK). Densitometric quantitation of bands was performed using Syngene Bio Imaging tools.

Oxygen consumption and extracellular acidification rates. Briefly, SKOV3 cells were plated at $8 \times 10^{4}$ cells/well in 96-multiwell, clear-bottom, black-body plates and allowed to adhere overnight. The following day, different concentrations of drugs were added and incubated for $6 \mathrm{~h}$. Each treatment was repeated in three wells. The determination of cell oxygen consumption and extracellular acidification rates was carried out using the fluorescent oxygen-sensitive and $\mathrm{pH}$-sensitive probes Mito-Xpress and pH-Xtra (Luxcel Bioscience, Cork, Ireland), respectively, as described previously (20).

Determination of glucose and lactate concentrations. Following treatment as indicated, the medium of SKOV3 cells was collected. The glucose and lactate concentrations were 
then determined with the glucose assay kit and the lactate assay kit (Bioassay Systems), respectively.

ATP measurements. Following treatment as indicated, the SKOV3 cells were lysed. After centrifugation, ATP concentrations were measured in the supernatant based on ATP-dependent luciferase activity with the ATP assay kit (Beyotime Biotechnology).

Glucose metabolism $R T^{2}$ profiler PCR array. The Human Glucose Metabolism RT ${ }^{2}$ Profiler $^{\mathrm{TM}}$ PCR array (SABiosciencesQiagen, Hilden, Germany) profiles the expression of 84 key genes involved in the regulation and enzymatic pathways of glucose and glycogen metabolism. Total cellular RNA was extracted from cultured cells according to the manufacturer's instructions. Single-stranded cDNA was obtained by reverse transcription of $1 \mu \mathrm{g}$ of total RNA using the SABiosciences $\mathrm{RT}^{2}$ First Strand kit. Real-time qPCRs were performed using Applied Biosystems 7300 Fast with SYBR Green Fluorophore. The reactions were carried out using $\mathrm{RT}^{2} \mathrm{SYBR}$ Green Mastermix. cDNA was used as template and cycling parameters were $95^{\circ} \mathrm{C}$ for $10 \mathrm{~min}$, followed by 40 cycles of $95^{\circ} \mathrm{C}$ for $15 \mathrm{sec}$ and $60^{\circ} \mathrm{C}$ for $1 \mathrm{~min}$. Fluorescence intensities were analyzed using the manufacturer's software, and relative quantification was calculated using the $2^{-\Delta \Delta \mathrm{Ct}}$ method. Change of expression of the 84 genes was shown by heat imaging. GAPDH was used as a reference gene.

Quantitative real-time PCR ( $q R T-P C R)$. Total RNA was extracted using TRIzol (Invitrogen, Carlsbad, CA, USA) according to the manufacturer's protocol. First-strand cDNAs were generated by reverse transcription of RNA samples with SuperScript preamplification system (Promega, Madison, MI, USA). Reverse transcribed products were used to amplify SIRT3 by qRT-PCR. qRT-PCR was performed using a FastStart Universal SYBR Green Master (Roche) on an ABI 7300 instrument. The primer sequences used for qRT-PCR were 5'-TGGAAAGCCTAGTGGAGCTTCTGGG-3' (forward) and 5'-TGGGGGCAGCCATCATCCTATTTGT-3' (reverse) for SIRT3, and 5'-GGGTGATGCTGGTGCTGAGTATGT-3 (forward) and 5'-AAGAATGGGAGTTGCTGTTGAAGT-3' (reverse) for GAPDH. The expression of each investigated gene was normalized to the housekeeping gene GAPDH. Data are presented as the fold change in gene expression relative to the control sample.

Measurement of intracellular $N A D^{+} / N A D H$ ratio. Both oxidized and reduced forms of intracellular nicotinamide adenine dinucleotide were determined using an NADH/NAD quantification kit (BioVision Inc., Milpitas, CA, USA) as described by the manufacturer. Briefly, $2 \times 10^{5}$ cells were washed with cold PBS, pelleted, and extracted with $400 \mu l$ of NADH/NAD extraction buffer by two freeze/thaw cycles. Samples were vortexed and centrifuged at 14,000 rpm for $5 \mathrm{~min}$. For each sample, a $200-\mu \mathrm{l}$ aliquot of extracted $\mathrm{NADH} / \mathrm{NAD}$ supernatant was transferred to a microcentrifuge tube. Samples were heated to $60^{\circ} \mathrm{C}$ for $30 \mathrm{~min}$ to allow decomposition of all $\mathrm{NAD}^{+}$while retaining $\mathrm{NADH}$ intact and then placed on ice. Samples were rapidly centrifuged and transferred to a multiwell-plate. Standards and a NAD cycling mix were prepared according to the manufacturer's protocol. An amount of $100 \mu \mathrm{l}$ of the reaction mix was added into each well of NADH standards and samples, and all samples were incubated at room temperature for $5 \mathrm{~min}$ to convert $\mathrm{NAD}^{+}$to NADH. NADH developer solution was added to each well, and plates were incubated at room temperature. The reaction was stopped by adding $10 \mu \mathrm{l}$ of stop solution into each well and mixing well, and absorbance was measured at $450 \mathrm{~nm}$.

Preparation of nuclear- and mitochondrial-enriched extracts. To generate fractions enriched in nuclear and mitochondrial proteins, $5.0 \times 10^{6}$ cells were harvested and washed in PBS. Cells were resuspended in $0.2 \mathrm{ml}$ of buffer MgRSB (10 mM $\mathrm{NaCl}, 1.5 \mathrm{mM} \mathrm{MgCl}{ }_{2}, 10 \mathrm{mM}$ Tris- $\mathrm{HCl}$ at $\mathrm{pH} 7.5,0.1 \mathrm{mM}$ PMSF, $1 \mathrm{mM}$ DTT) and incubated on ice for $10 \mathrm{~min}$. Cells were dounced to yield free nuclei, and $0.034 \mathrm{ml}$ of sucrose buffer (2 $\mathrm{M}$ sucrose, $35 \mathrm{mM}$ EDTA, $50 \mathrm{mM}$ Tris- $\mathrm{HCl}$ at $\mathrm{pH}$ 7.5) was immediately added. Free nuclei were collected by centrifugation at $1,000 \mathrm{~g}$ for $10 \mathrm{~min}$. Mitochondria were collected by centrifugation at $11,000 \mathrm{~g}$ for $10 \mathrm{~min}$. Nuclei were resuspended in buffer $\mathrm{C}(20 \mathrm{mM}$ Tris- $\mathrm{HCl}$ at $\mathrm{pH} 7.9,25 \%$ glycerol, $0.42 \mathrm{M}$ $\mathrm{NaCl}, 1.5 \mathrm{mM} \mathrm{MgCl}_{2}, 0.2 \mathrm{mM}$ EDTA, $0.1 \mathrm{mM}$ PMSF, $0.5 \mathrm{mM}$ DTT) and incubated on ice for $20 \mathrm{~min}$. To generate nuclear extract, nuclei were spun down at 14,000 g, and the supernatant was collected. Mitochondria were resuspended in buffer $\mathrm{C}$ to be used in western blot analyses.

Immunofluorescent confocal laser microscopy. SKOV3 cells were cultured on coverslips at a density of $5 \times 10^{4}$ cells/well in $500 \mu \mathrm{l}$ of complete medium. After treatment, SKOV3 cells were washed with cold PBS three times and fixed in $4 \%(\mathrm{w} / \mathrm{v})$ paraformaldehyde/PBS for 20 min then washed with cold PBS three times. Fixed cells were digested by protein enzyme K for 1 min and washed with PBS twice. Cells were incubated with $0.1 \%$ (v/v) Triton X-100 for 6-10 min, washed once with PBS, and then blocked for $30 \mathrm{~min}$ in $5 \%(\mathrm{v} / \mathrm{v})$ non-immune animal serum/PBS. Cells were incubated with primary antibody (SIRT3, Tom20, dilution 1:200; Santa Cruz Biotechnology) overnight and washed three times with PBS. Cells were then incubated with secondary antibody (rabbit and mouse, dilution 1:400; Thermo, Waltham, MA, USA) for $30 \mathrm{~min}$ in the dark. Plates were washed three times in PBS, treated with Hoechst $33342 / \mathrm{H}_{2} \mathrm{O}(1 \mu \mathrm{g} / \mathrm{ml})$ for $2 \mathrm{~min}$, and then washed three times with PBS. Cells were examined by Olympus FV1000 confocal laser microscope.

SIRT3 knockdown by small interfering. RNA Small interfering RNA (siRNA) sequences targeting human SIRT3 (GenBank accession no. NM_012239) and a non-target sequence were constructed by Genechem (Shanghai, China). The SIRT3-RNAi (23504) sequence was GCTTGATGGACCAGACAAA, SIRT3RNAi (23505) sequence was GCTGTACCCTGGAAACTAC, SIRT3-RNAi (23506) sequence was ACCTCCAGCAGTACG ATCT, and SIRT3-RNAi (23507) sequence was TCGATGGGC TTGAGAGAGT. The non-target siRNA (Scramble) sequence was TTCTCCGAACGTGTCACGT. Transfections with siRNA were performed using Lipofectamine 2000 (Invitrogen) according to the manufacturer's protocol. Briefly, SKOV3 cells were placed into 6-well plates, and transfected the next day with $4 \mu \mathrm{g}$ si-SIRT3 or si-Scramble, using $10 \mu \mathrm{l}(1 \mu \mathrm{g} / \mu \mathrm{l})$ 

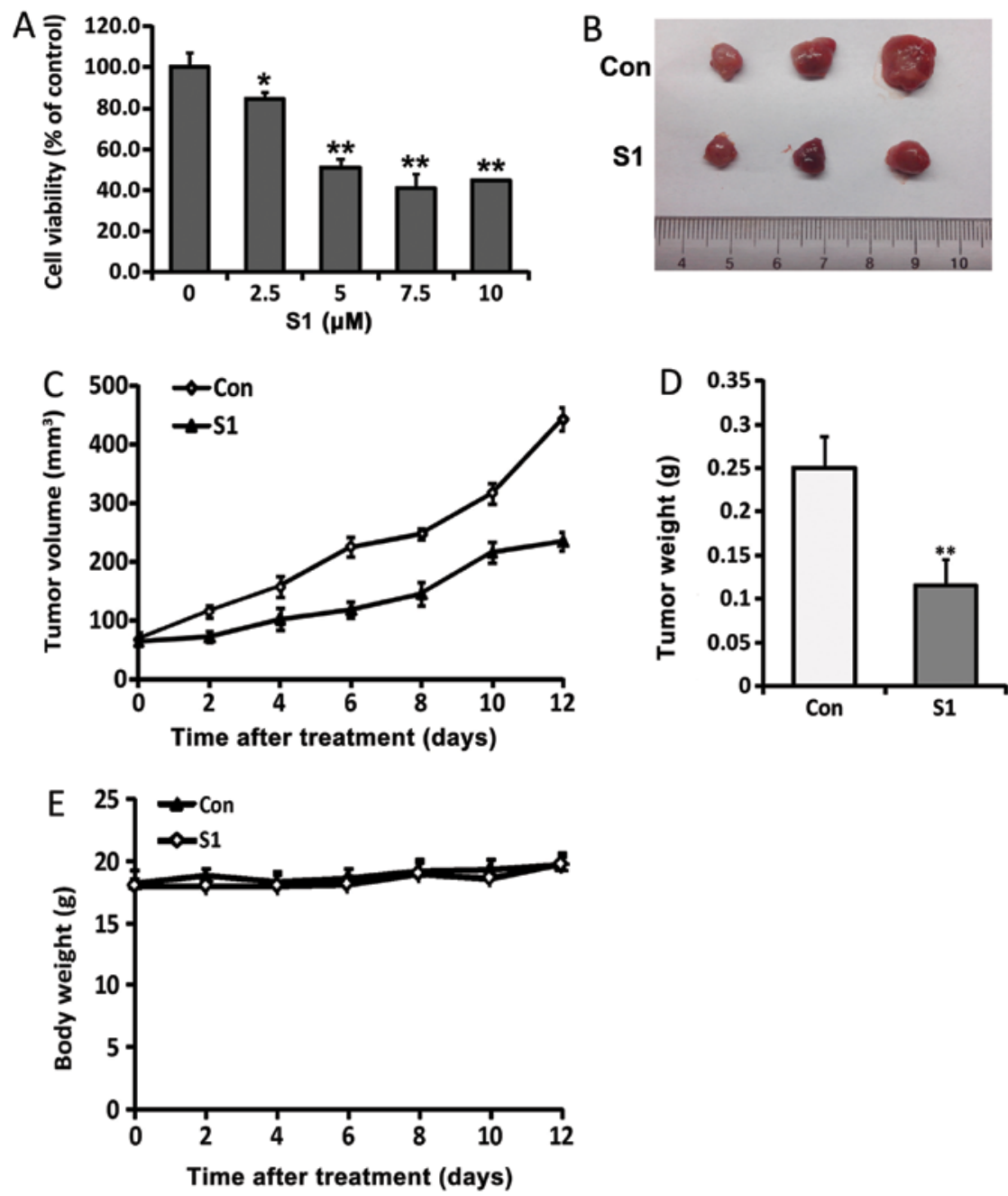

Figure 1. S1 inhibits the proliferation of SKOV3 cells and tumor growth in a subcutaneous xenograft model. (A) SKOV3 cells were treated with varying doses of S1 for $24 \mathrm{~h}$. Cell viability was determined by MTT assay. Data are presented as mean \pm SD $(n=3)$. (B) Representative images of SKOV3 cell xenografts. SKOV3 cells were subcutaneously implanted into nude mice. Each treatment group consisted of six to eight mice treated with vehicle or $6 \mathrm{mg} / \mathrm{kg}$ S1 for 12 days, after which tumor growth was measured. (C) The tumor volume was calculated from the measurements. Points, means; bars, \pm SE. (D) Wet weights of the tumors were determined at autopsy. Columns represent mean of six to eight tumors from vehicle- and S1-treated mice. ${ }^{* *} \mathrm{P}<0.01$ compared with vehicle group. (E) Body weight gain profiles of vehicle- and S1-treated mice. Body weight is represented as mean of six mice in vehicle- or S1-treated mice.

Lipofectamine 2000. Cells were harvested 2 days after transfection; whole cell lysates were isolated for western blot analyses. For MTT assay, transfected cells were treated with $\mathrm{S} 1$ for $24 \mathrm{~h}$, followed by MTT assay to determine cell viability.

Morphological assessment. Cells were seeded at $2.0 \times 10^{5}$ cells/ well in 6-well cell culture dishes and treated with experimental conditions, as indicated in the individual figures, during their logarithmic growth phase. After various treatments and timepoints, morphological alterations were analyzed under an inverted phase contrast microscope (Olympus, Tokyo, Japan) at $\times 20$ magnification.

Caspase-3/7 activity. Caspase-3/7 activity was measured using the Caspase-Glo 3/7 assay kit (Promega) according to the manufacturer's instructions. Each experiment was performed in quintuplicate and experiments were carried out twice.

Statistical analysis. Data are expressed as the mean \pm SD. SPSS 17.0 software was used for analysis. All experiments were repeated at least three times. The statistical significance of the difference between two groups was assessed using Student's t-test, and $\mathrm{P}<0.05$ was considered to be significant.

\section{Results}

BH3 mimetic S1 inhibits the proliferation of SKOV3 cells and tumor growth in a xenograft model of ovarian cancer. SKOV3 cells were treated with different doses of S1 for $24 \mathrm{~h}$, and the survival rate was then examined using MTT assays. The viability of SKOV3 cells was shown to be decreased by S1 treatment (Fig. 1A). To initiate the treatment on palpable tumors, SKOV3 xenografts were inoculated subcutaneously into Balb/c nude mice. S1 was then injected 7 days later, and shown to significantly inhibit the growth of tumor xenografts compared with vehicle-treated controls. At sacrifice, the mean tumor volumes in animals treated with $\mathrm{S} 1$ were $235 \mathrm{~mm}^{3}$ compared with $443.3 \mathrm{~mm}^{3}$ for control animals (Fig. 1C), while mean tumor weights were 0.116 and $0.25 \mathrm{~g}$, respectively (Fig. 1D). Notably, there was no overt gross toxicity in either 
vehicle- or S1-treated mouse, as determined by measuring body weights (Fig. 1E).

Ovarian tumor growth was compared between animals with and without S1 treatment. The direct measurement of tumor volume was performed at the start of tumor inoculation. After S1 treatment, a significant reduction in tumor volume and weight was observed compared with the vehicle-treated control (Fig. 1B-D). We found that $6 \mathrm{mg} / \mathrm{kg}$ of S1 caused a reduction in tumor growth of $53.7 \%$ compared with the vehicle-treated control group, while it had no adverse effects on body weight, indicating that it lacked potential toxicity in nude mice. These results indicate that $\mathrm{S} 1$ inhibits SKOV3 cell proliferation and retards the growth of SKOV3 xenografts in vivo.

S1 induces apoptosis and inhibits mitochondrial respiration and glycolysis in ovarian cancer cells. Based on MTT results, we treated SKOV3 cells with $5 \mu \mathrm{M} \mathrm{S} 1$ for 6,12 and $24 \mathrm{~h}$, and detected apoptotic chromatin condensation by Hoechst 33342 staining using confocal microscopy. S1-induced apoptotic chromatin condensation was obviously seen after 12-h treatment (Fig. 2A). We next examined the apoptotic effects through detecting the expression of Bcl-2, Mcl-1, cytoplasmic cytochrome $c$ and the activation of caspase-3 and PARP by western blotting. S1 decreased the expression of Bcl-2 and Mcl-1, and enhanced expression of cleaved caspase-3, cleaved PARP and cytoplasmic cytochrome $c$ in SKOV3 cells (Fig. 2B and $\mathrm{C}$ ). These results indicate that $\mathrm{S} 1$ efficiently induces apoptosis in SKOV3 cells.

Previous studies showed that aerobic glycolysis is important for the growth of ovarian tumors (13). To determine whether S1 affects glucose metabolism before exerting obvious cytotoxity such as the induction of apoptosis, we first analyzed its effects on oxygen consumption rate (OCR) and extracellular acidification rates (ECAR) in SKOV3 cells after short-term exposure for $6 \mathrm{~h}$ (Fig. 2D and E). Following the inhibition of mitochondrial respiration by antimycin $\mathrm{A}$ in SKOV3 cells, we observed a drop in OCR, whereas ECAR increased. We also found that $\mathrm{S} 1$ induced a significant decrease in OCR, whereas ECAR increased slightly. Moreover, the effects of several different Bcl-2 inhibitors, including ABT-737, ABT-199 and obatoclax mesylate (oba), were also observed. ABT-737 showed no obvious effect on either OCR or ECAR, while ABT-199 and oba induced an increase in both OCR and ECAR. These results indicate that the effects of different Bcl-2 inhibitors on glucose metabolism are specific, and S1 mainly inhibits mitochondrial respiration in SKOV3 cells before exerting obvious cytotoxity.

We next determined cellular metabolic profiles by measuring extracellular glucose and lactate levels. Compared with the control group, S1-treated cells showed a decreased glycolytic phenotype with significantly lower glucose consumption and lactate production after long-term exposure for $12 \mathrm{~h}$ (Fig. 2F and G). Because glycolysis and mitochondrial respiration are the two main sources of cellular ATP production, we assessed whether S1 affected ATP levels. S1 was shown to decrease ATP levels in a dose-dependent manner (Fig. 2H). Taken together, these results suggest that S1 inhibits mitochondrial respiration and glycolysis and induces apoptosis in SKOV3 cells.
Array analysis reveals $S 1$-induced regulation of glucose metabolism-related gene expression. To gain further insight into the regulation of glucose metabolism by $\mathrm{S} 1$, the expression levels of the human glucose metabolism-related genes were examined in SKOV3 cells treated by S1 (5 $\mu \mathrm{M}, 6$-h exposure) using the $\mathrm{RT}^{2}$ Human Glucose Metabolism Profiler PCR array technology.

As shown in Fig. 3, significant downregulation of gene expression indicative of glycolysis was induced by S1 including hexokinase 2 (HK-2; position C7), liver phosphofructokinase (PFKL; position E5) and pyruvate dehydrogenase kinase isozyme 2 (PDK2; position D12), consistent with the detection of S1-induced inhibition of glucose uptake and lactate secretion (as detailed in Fig. 2). Upregulation of hexose-6-phosphate dehydrogenase (H6PD; position $\mathrm{C6}$ ), which is responsive to the pentose phosphate pathway, was observed. S1 also affected tricarboxylic acid (TCA) cycle encoding genes [upregulation of ATP citrate lyase (ACLY; position A1), aconitase 1 (ACO1; position A2), dihydrolipoamide S-acetyltransferase (DLAT; position A10), isocitrate dehydrogenase 2 (IDH2; position $\mathrm{C} 10$ ), isocitrate dehydrogenase $3 \alpha$ (IDH3A; position $\mathrm{C} 11$ ), malate dehydrogenase 1B (MDH1B; position D3), malate dehydrogenase $2(\mathrm{MDH} 2$; position $\mathrm{D} 4)$, oxoglutarate $\alpha$-ketoglutarate ehydrogenase (OGDH; position D5), succinate dehydrogenase complex subunit C (SDHC; position G4), succinate-CoA ligase GDP-forming $\beta$ subunit (SUCLG2; position G8)]. In addition, S1-treatment changed expression of genes encoding enzymes involved in gluconeogenesis [upregulation of fructose-1,6-bisphosphatase 1 (FBP1; position B4), fructose-1,6-bisphosphatase 2 (FBP2; position B5), glucose-6-phosphatase catalytic subunit (G6PC; position B7), phosphoenolpyruvate carboxykinase 1 (PCK1; position D7), phosphoenolpyruvate carboxykinase 2 (PCK2; position D8)], together with downregulation of glucose 6 phosphatase catalytic 3 (G6PC3; position B8)]. The array results show that S1 inhibits glycolysis and activates gluconeogenesis and TCA cycle at the mRNA level in SKOV3 cells.

Mitochondrial localization of SIRT3 is promoted by SI treatment. SIRT3, a mitochondrial stress protein, is a key regulator of cancer metabolism and apoptosis (21). Because S1 inhibited mitochondrial respiration and glycolysis and induced apoptosis in SKOV3 cells, we considered whether SIRT3 was involved in this role. By observing the gene and protein expression of SIRT3, we found that S1 upregulated SIRT3 in a time-dependent manner (Fig. 4A-C). As NAD ${ }^{+}$is an important cofactor for the activation of SIRT3, we also checked whether the intracellular $\mathrm{NAD}^{+} / \mathrm{NADH}$ ratio was modulated by $\mathrm{S} 1$. We found that $\mathrm{S} 1$ effectively increased the intracellular $\mathrm{NAD}^{+} / \mathrm{NADH}$ ratio, which may contribute to the activation of SIRT3 (Fig. 4D).

Although SIRT3 has been reported to be exclusively expressed in mitochondria (14), another study showed that it may exist in the nucleus and translocate to the mitochondria under stress (22). In this study, western blot analysis and immunofluorescence studies of the protein expression of SIRT3 suggested that S1 induced the SIRT3 translocation from the nucleus to mitochondria (Fig. 4E-G). A decrease in the nuclear expression of SIRT3 was matched by an increase in its colocalization with TOM20, a mitochondrial marker. These 

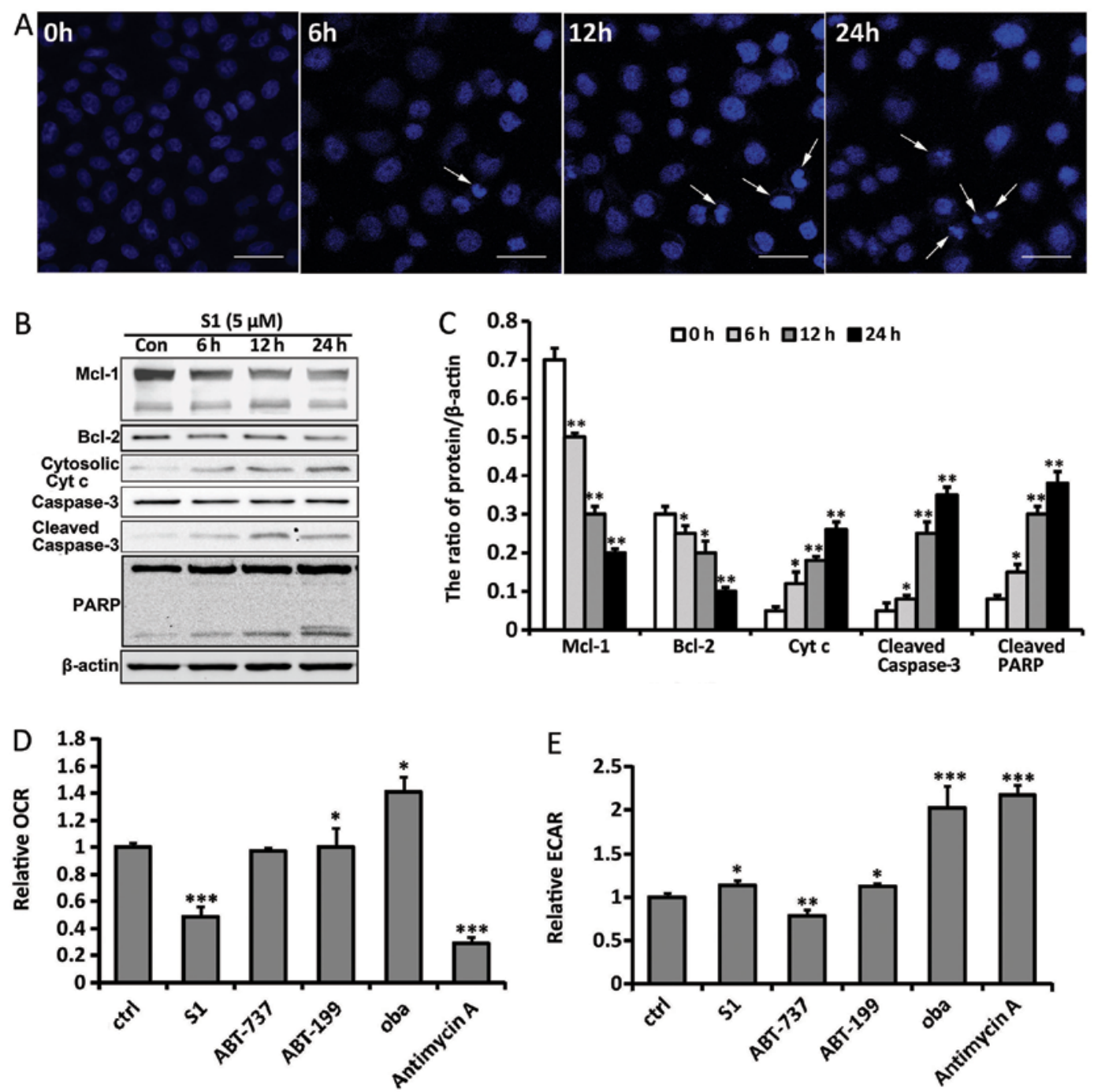

$\mathrm{E}$
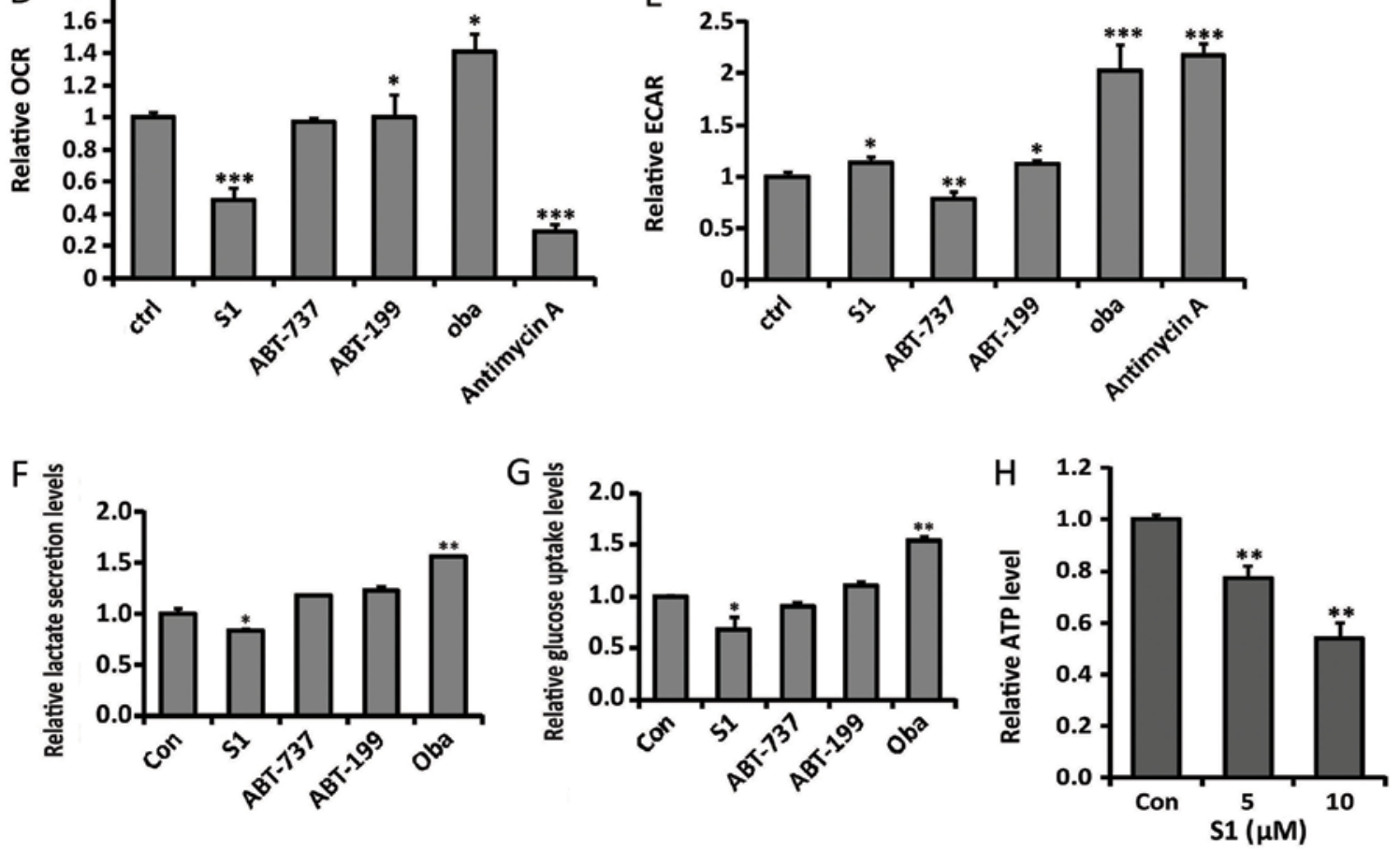

Figure 2. S1 induces apoptosis and interrupts glucose metabolism in SKOV3 cells. (A) SKOV3 cells were treated with $5 \mu \mathrm{M} \mathrm{S1}$ for 6,12 and $24 \mathrm{~h}$, and stained with Hoechst 33342. Cell morphology was observed by confocal microscopy (bar, $10 \mu \mathrm{m}$; arrows, apoptotic cells). (B) Western blot analysis for the expression of Bcl-2, Mcl-1, caspase-3, PARP and cytosolic cytochrome $c$ protein in SKOV3 cells treated with S1. (C) Quantitation of Bcl-2, Mcl-1, cleaved caspase-3, cleaved PARP and cytosolic cytochrome $c$ protein levels. Data were presented as mean $\pm \mathrm{SD}, \mathrm{n}=3,{ }^{*} \mathrm{P}<0.05,{ }^{* *} \mathrm{P}<0.01$ compared with control group. Oxygen consumption rates (D) and extracellular acidification rates (E) were measured in the presence of Bcl-2 inhibitors or antimycin $\mathrm{A}(2.5 \mu \mathrm{M}){ }^{*} \mathrm{P}<0.05$, ${ }^{* *} \mathrm{P}<0.01$, ${ }^{* * *} \mathrm{P}<0.001$ compared with control group $(\mathrm{n}=4)$. Extracellular glucose $(\mathrm{F})$ and lactate $(\mathrm{G})$ concentrations were determined enzymatically in the culture media and expressed as a relative metabolite concentration after indicated times and after normalization to protein content. "P<0.05, compared with control group $(\mathrm{n}=3)$. $(\mathrm{H})$ ATP production after treatment with different doses of $\mathrm{S} 1$ relative to the control group. ${ }^{* *} \mathrm{P}<0.01$ compared with the control group ( $\left.\mathrm{n}=3\right)$.

results indicate that $\mathrm{S} 1$ upregulates the expression of SIRT3 and induces its translocation from the nucleus to mitochondria.

SIRT3 activation contributes to S1-induced apoptosis and glycolysis inhibition. To examine the role of SIRT3 activation after S1 treatment, we first used small interfering (si)RNA to knockdown SIRT3 expression, and then determined the effects of this on S1-induced growth inhibition. We transfected SKOV3 cells with siRNA against SIRT3 or non-target sequence for 48 h. As shown in Fig. 5A, the SIRT3 protein expression was 

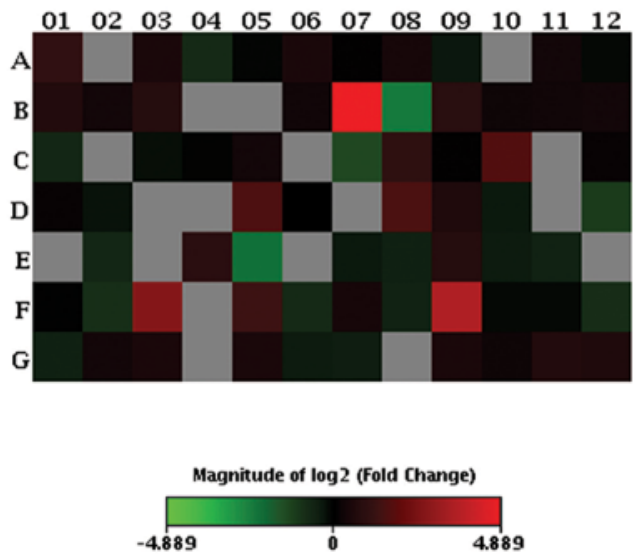

Functional Gene Grouping

Glucose Metabolism:

Glycolysis: ALDOA, ALDOB, ALDOC, BPGM, ENO1, ENO2, ENO3, GALM, GCK, GPI, HK2, HK3, PFKL, PGAM2, PGK1, PGK2, PGM1,

PGM2, PGM3, PKLR, TPI1.

Gluconeogenesis: $\mathrm{FBP} 1, \mathrm{FBP} 2, \mathrm{G} 6 \mathrm{PC}, \mathrm{G} 6 \mathrm{PC} 3, \mathrm{PC}, \mathrm{PCK} 1, \mathrm{PCK} 2$

Regulation: PDK1, PDK2, PDK3, PDK4, PDP2, PDPR.

TCA Cycle: ACLY, ACO1, ACO2, CS, DLAT, DLD, DLST, FH, IDH1, IDH2, IDH3A, IDH3B, IDH3G, MDH1, MDH1B, MDH2, OGDH, PC,

PCK1, PCK2, PDHA1, PDHB,SDHA, SDHB, SDHC, SDHD, SUCLA2,

SUCLG1,SUCLG2.

Pentose Phosphate Pathway: G6PD, H6PD, PGLS, PRPS1, PRPS1L1, PRPS2, RBKS, RPE, RPIA, TALDO1, TKT.

Glycogen Metabolism:

Synthesis: GBE1, GYS1, GYS2, UGP2.

Degradation:AGL, PGM1, PGM2, PGM3, PYGL, PYGM.

Regulation: GSK3A, GSK3B, PHKA1, PHKB, PHKG1, PHKG2.

Figure 3. Human glucose metabolism PCR arrays reveals up- and downregulated genes in SKOV3 cells. SKOV3 cells were treated with $5 \mu \mathrm{M} \mathrm{S1}$ for $6 \mathrm{~h}$ and the expression of the glucose metabolism-related genes ( 84 genes) were examined using a PCR array. For gene name details see supporting information. Changes are presented as heat images. Green indicates downregulation, and red indicates upregulation. Data are derived from three experiments.

A
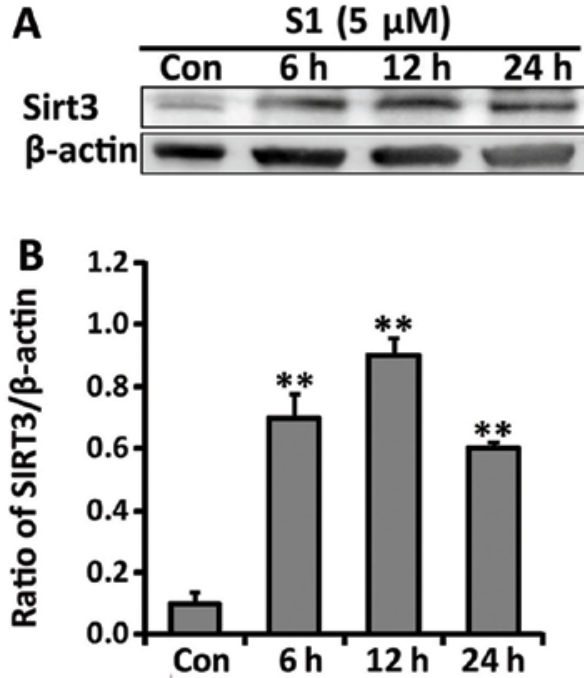

$\mathbf{E}$
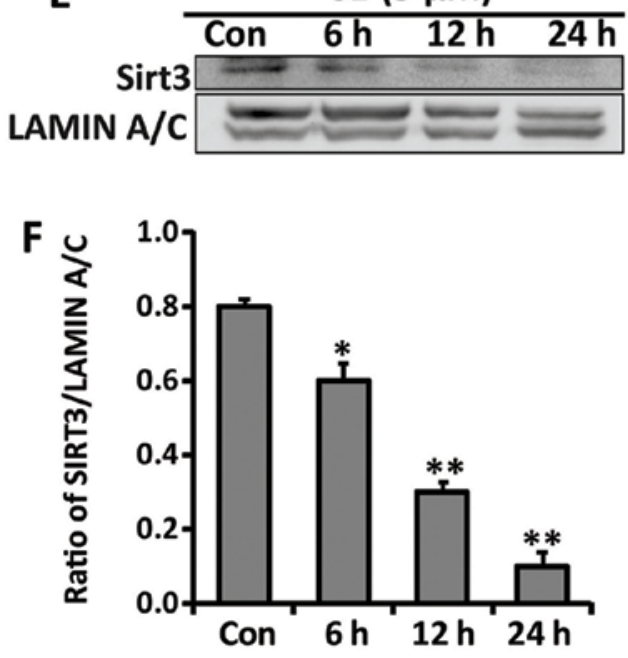
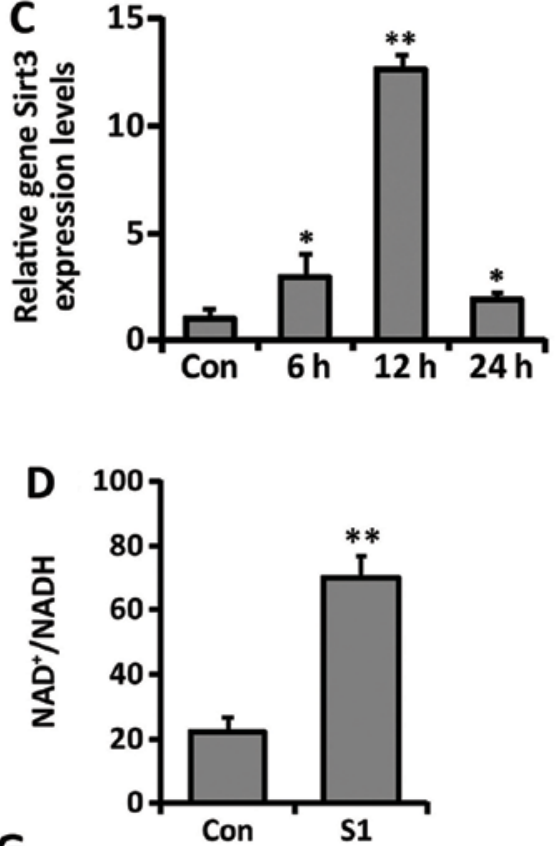

G

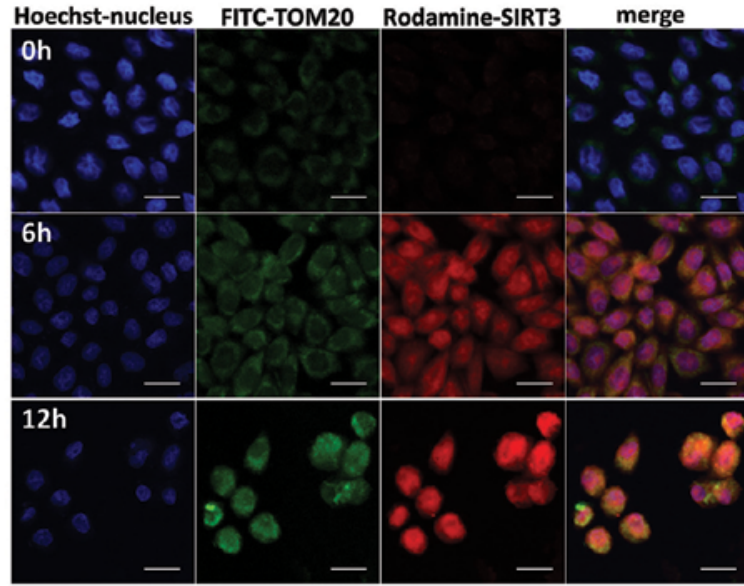

Figure 4. S1 upregulates the expression of SIRT3 and induces SIRT3 translocation. (A) Western blot analysis of the expression of SIRT3 protein in SKOV3 cells treated with $5 \mu \mathrm{M}$ S1. (B) Quantitation of SIRT3 protein level. Data are presented as mean $\pm \mathrm{SD}, \mathrm{n}=3,{ }^{* *} \mathrm{P}<0.01$ compared with control group. (C) Real-time RT-PCR analysis of the mRNA expression of SIRT3 in SKOV3 cells treated with $\mathrm{S} 1 .{ }^{*} \mathrm{P}<0.05,{ }^{* *} \mathrm{P}<0.01,{ }^{* * *} \mathrm{P}<0.001$ compared with control group (n=3). (D) $\mathrm{NAD}^{+}$and NADH in cell extracts were quantified as described in Materials and methods. The optical density at $450 \mathrm{~nm}$ was used to calculate the NAD ${ }^{+}$ NADH ratio. (E) Western blot analysis of SIRT3 protein expression in nuclear extracts. (F) Quantitation of SIRT3 protein level normalized to lamin A/C. Data are presented as mean $\pm \mathrm{SD}, \mathrm{n}=3,{ }^{*} \mathrm{P}<0.05,{ }^{* *} \mathrm{P}<0.01$ compared with control group. (G) The colocalization of SIRT3 and Tom 20 in SKOV3 cells treated with $5 \mu \mathrm{M} \mathrm{S} 1$ (bar, $10 \mu \mathrm{m})$. 
A

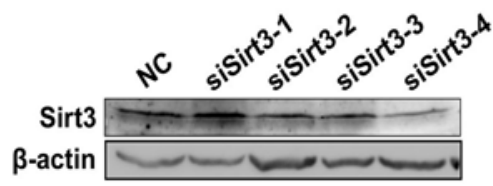

B

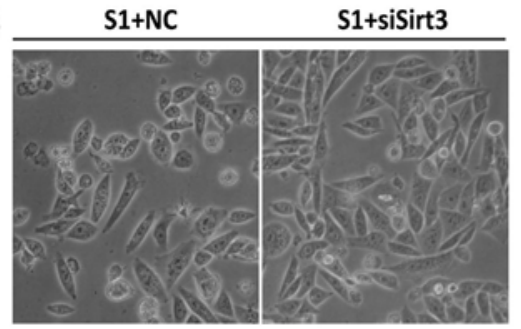

C

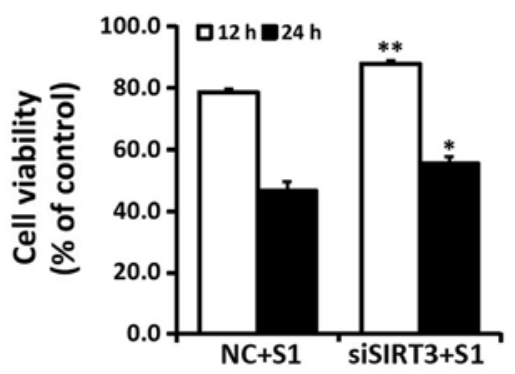

D
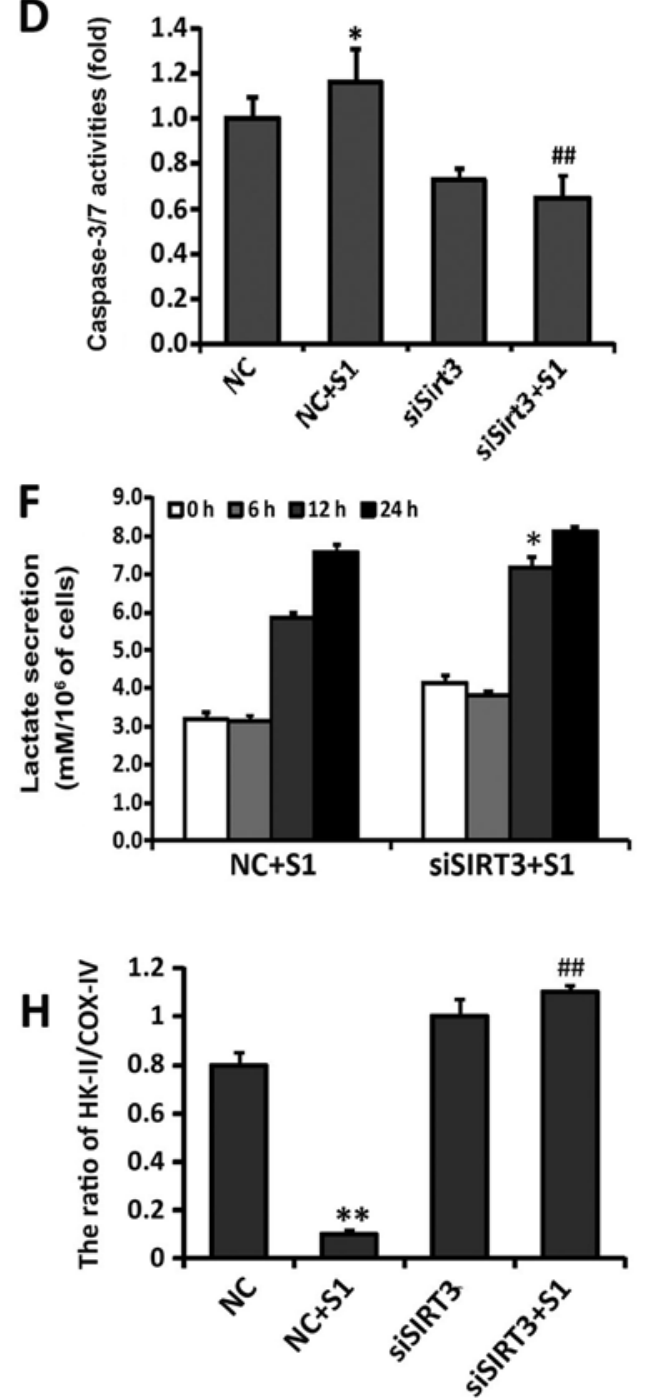

Figure 5. Knockdown of SIRT3 decreases S1-induced cell death and alleviates the inhibition of glycolysis. SKOV3 cells were transfected with SIRT3 siRNA (siSIRT3) and non-target sequence siRNA (NC). (A) Western blot analyzed the knockdown efficiency of the four siRNAs targeting SIRT3. SKOV3 cells were transfected with siSIRT3 (siSIRT3-23504, siSIRT3-23505, siSIRT3-23506 and siSIRT3-23507) and NC for $48 \mathrm{~h}$, respectively. (B) Cell morphology was observed using an optical microscope (bar, $50 \mu \mathrm{m})$. (C) Cell viability was determined by MTT assay. Data are presented as mean $\pm \mathrm{SD}(\mathrm{n}=3)$. ${ }^{*} \mathrm{P}<0.05,{ }^{* *} \mathrm{P}<0.01$ compared with the S1-treated NC group. (D) Caspase-3/7 activities in transfected SKOV3 cells treated with or without S1. Data are the mean \pm SEM (n=3). ${ }^{*} \mathrm{P}<0.05$ vs. the NC group, ${ }^{\# \#} \mathrm{P}<0.01$ vs. the S1-treated NC group. Extracellular glucose (E) and lactate (F) concentrations were determined enzymatically in the culture media and expressed as a relative metabolite concentration after indicated times and after normalization to protein content. ${ }^{*} \mathrm{P}<0.05$, compared with control group ( $\mathrm{n}=3$ ). (G) Western blot analysis of HK-II protein expression in the mitochondria of transfected SKOV3 cells treated with or without S1. (H) Quantitation of SIRT3 protein level normalized to COX-IV. Data were presented as mean $\pm \mathrm{SD}, \mathrm{n}=3,{ }^{*} \mathrm{P}<0.05$ vs. the NC group, ${ }^{\# \#} \mathrm{P}<0.01$ vs. the $\mathrm{S} 1$-treated $\mathrm{NC}$ group.

significantly decreased in siSIRT3-23507 group compared with cells transfected with control siRNA, and we adopted this effective siRNA to knockdown SIRT3 expression. Importantly, SIRT3 knockdown alleviated S1-induced growth inhibition compared with control siRNA cells (Fig. 5B and C).
Next, we assessed the role of SIRT3 in S1-induced apoptosis. After 24-h treatment with $5 \mu \mathrm{M} \mathrm{S1}$, a significant decrease in caspase-3/7 activity was shown in siSIRT3-SKOV3 cells compared with cells transfected with control siRNA (Fig. 5D). To further investigate whether the activation of SIRT3 is 

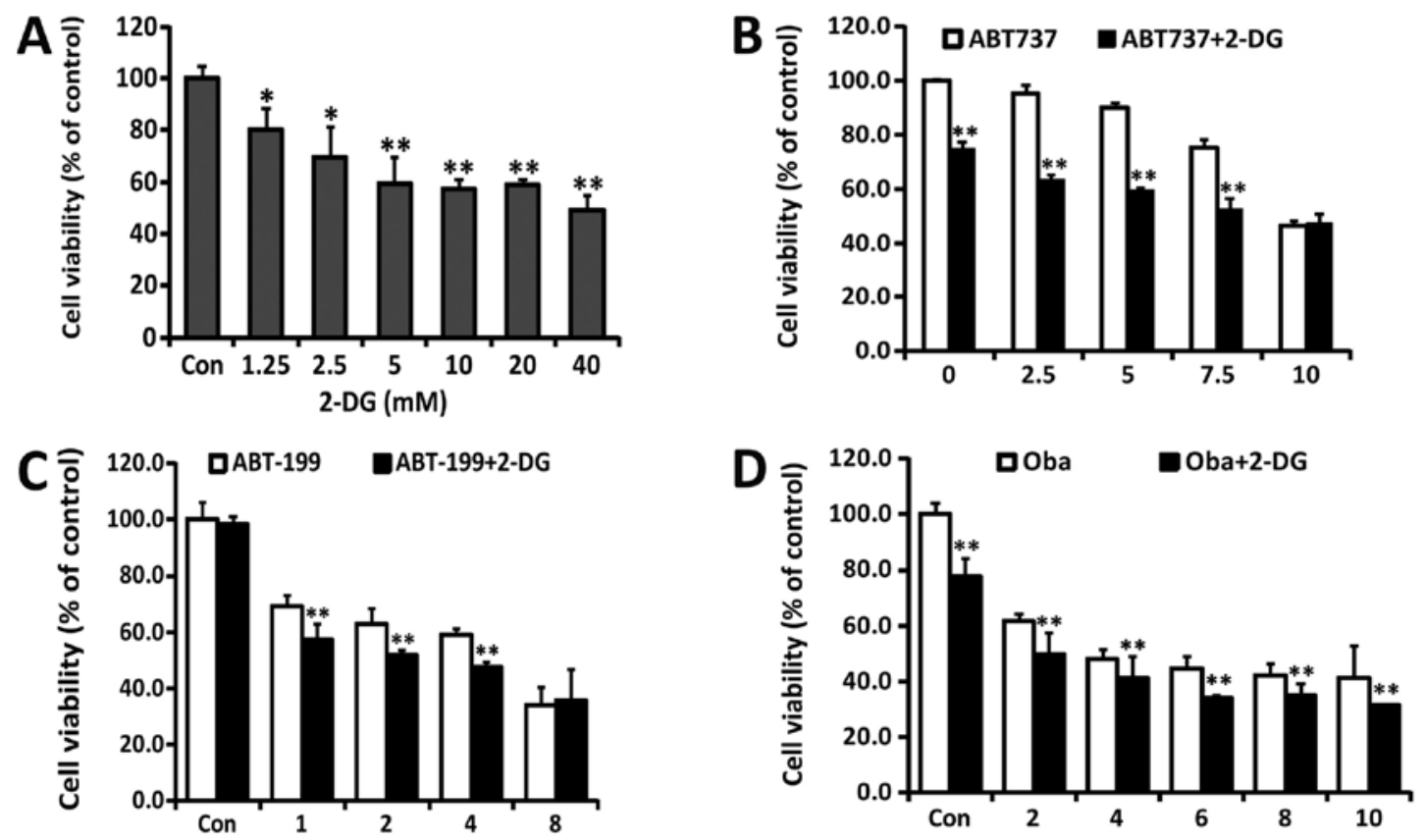

$\mathbf{F}$
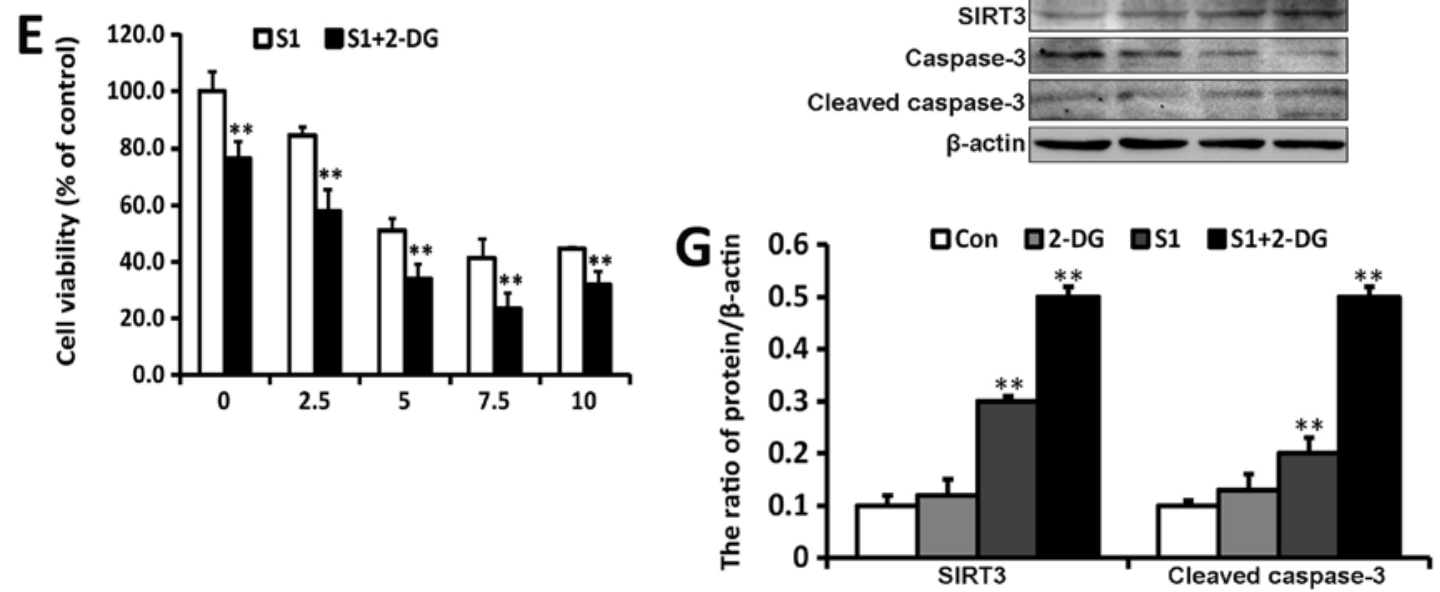

Figure 6. Inhibition of cell glycolysis enhanced S1-induced apoptosis. (A-E) SKOV3 cells were treated with different doses of 2-DG for $24 \mathrm{~h}$, or different doses of Bcl-2 inhibitors and/or 2-DG $(1.25 \mathrm{mM})$ for $24 \mathrm{~h}$. Cell viability was determined by MTT assay. Data are presented as mean $\pm \mathrm{SD}, \mathrm{n}=3$. ${ }^{*} \mathrm{P}<0.05,{ }^{* * *} \mathrm{P}<0.01$ versus control group. (F) Western blot analysis of the expression of SIRT3 and the activation of caspase-3 in SKOV3 cells treated with S1 and/or 2-DG for 24 h. (G) Quantitation of SIRT3 and cleaved caspase-3 protein levels. Data are presented as mean $\pm \mathrm{SD}, \mathrm{n}=3,{ }^{*} \mathrm{P}<0.05,{ }^{* *} \mathrm{P}<0.01$ versus control group.

involved in the regulation of glucose metabolism by $\mathrm{S} 1$, we examined cellular metabolic profiles by measuring extracellular glucose and lactate levels in the growth media of SKOV3 cells transfected with siRNA against SIRT3 or non-target sequence. The consumption of glucose and lactate secretion after 12-h treatment with S1 were considerably higher in siSIRT3-SKOV3 than control-transfected cells (Fig. 5E and F). Previous research found that a potential anticancer drug Oroxylin A could inhibit glycolysis and induce the dissociation of hexokinase II from the mitochondria in human breast carcinoma cell lines, which is related to the activation of SIRT3 (23). We also checked whether the activation of SIRT3 induced by S1 could affect the expression of HK-II in the mitochondria. As shown in Fig. 5G, compared with control transfected group, knockdown of SIRT3 increased the expression of HK-II in the mitochondria after S1 treatment. These results indicate that the activation of SIRT3 exerts a proapoptotic role in S1-treated SKOV3 cells, and may contribute to the regulation of glucose metabolism by $\mathrm{S} 1$.

Combination of S1 with glycolysis inhibitor 2-DG aggravates apoptosis. In MTT assays, use of a combination of 2-DG with Bcl-2 inhibitors such as ABT737, ABT199, Oba, and S1 inhibited cell viability to a greater extent than that of cells treated only with Bcl-2 inhibitors (Fig. 6A-E). To determine the effect on apoptosis, we examined the activation of caspase- 3 in SKOV3 cells treated with S1 and/or 2-DG for $24 \mathrm{~h}$ (Fig. 6F). 2-DG upregulated the activation of caspase 3 induced by S1, which correlated with the upregulation of SIRT3 (Fig. 6G). These results demonstrated that the manipulation of $\mathrm{Bcl}-2$ inhibitors combined with the use of classic glycolysis inhibitors may be rational strategies to improve ovarian cancer 
therapy through glycolysis inhibition and targeting mitochondrial apoptotic machinery.

\section{Discussion}

During ovarian cancer progression cells become more glycolytic (24), so metabolic interventions have been proposed as promising treatment strategies (13). We previously demonstrated that the $\mathrm{BH} 3$ mimetic $\mathrm{S} 1$ induces endoplasmic reticulum stress-associated apoptosis through activating the c-Jun $\mathrm{N}$-terminal kinase (JNK) signaling pathway in human ovarian cancer cells (25). However, the effect of S1 on ovarian cancer cell metabolism remained unclear. In this study, we found that SIRT3, which is involved in the reprogramming of metabolism and apoptosis, was upregulated in S1-treated SKOV3 cells. Moreover, our data also showed that $\mathrm{S} 1$ interrupted glucose metabolism by inhibiting mitochondrial respiration and glycolysis in SKOV3 cells. PCR array results demonstrated that $\mathrm{S} 1$ inhibited glycolysis and activated gluconeogenesis and TCA cycle at the mRNA level, suggesting the involvement of metabolic regulation in S1-induced cytotoxicity. Moreover, SIRT3 knockdown using siRNA alleviated S1-induced apoptosis and glycolysis inhibition. The combination of S1 with the classic glycolysis inhibitor 2-DG appeared to intensify the antitumor effects of S1 through further upregulation of SIRT3 expression in ovarian cancer cells. These results indicate that $\mathrm{S} 1$ exerts anticancer roles in SKOV3 cells through the interruption of glucose metabolism and induction of apoptosis involving the activation of SIRT3.

Other groups have shown that antiapoptotic proteins such as Bcl-xL and Mcl-1 may exert regulatory roles in both cellular metabolism and apoptosis (26,27). The classic Bcl-2 inhibitor ABT737 has been demonstrated to target oxidative phosphorylation and selectively eradicate quiescent human leukemia stem cells (6). In this study, we found that S1 exerted cytotoxicity against ovarian cancer both in vitro and in vivo (Fig. 1). To investigate whether the effects of S1 on glucose metabolism are involved in its cytotoxicity, we measured the OCR, which is indicative of mitochondrial respiration, and the ECAR, which is indicative of glycolysis. Early responses to S1 exposure $(6 \mathrm{~h})$ involved a significant decrease in OCR and a slight increase in ECAR (Fig. 2). By measuring extracellular metabolites, we found that glucose consumption and lactate production were reduced after a long exposure to S1 (12 h) (Fig. 2). The glucose metabolism-related gene expression array analysis further demonstrated that $\mathrm{S} 1$ treatment inhibited glycolysis (Fig. 3). These results indicate that S1 inhibits mitochondrial respiration and glycolysis in SKOV3 cells. Upon addition of other Bcl-2 inhibitors such as ABT-737, ABT-199 and oba, the cellular respiration and acidification demonstrated different changes, which may be related to their respective specific target. These results indicate that it is necessary to study the effects of different types of Bcl-2 inhibitors on the metabolism.

Because oxidative phosphorylation and glycolysis are the main intracellular sources of adenosine triphosphate (ATP) production (28), we next checked the effect of S1 on ATP production. Our results showed that $\mathrm{S} 1$ inhibited ATP production in SKOV3 cells (Fig. 2). Thus, it appears that the Bcl-2 inhibitor S1 affects cellular metabolism through inhibiting mitochondrial respiration and glycolysis, leading to a decrease in ATP production. Intracellular ATP levels have been shown to be a pivotal determinant of chemoresistance in colon cancer cells (29). Interruption of ATP levels through targeting glycolysis or inhibiting ATP citrate lyase can suppress tumor cell growth $(30,31)$. Our results showed that $\mathrm{S} 1$ downregulates the intracellular ATP level in SKOV3 cells, which may be intertwined with its antitumor effects.

SIRT3 was initially thought to be an important mitochondrial nicotinamide adenine dinucleotide $\left(\mathrm{NAD}^{+}\right)$-dependent deacetylase (14) that regulates the mitochondrial adaptive response to stress through antioxidant defense mechanisms (16). Indeed, it was reported to be activated in myocytes during genotoxic and oxidative stress (32). SIRT3 expression was also found to be increased after Bcl-2 silencing in HCT116 human epithelial cancer cells through the JNK pathway (17). We previously showed that S1 induces oxidative stress and activates the JNK pathway in ovarian cancer cells (33). In this study, S1 was shown to upregulate the expression of SIRT3 in SKOV3 cells. We also observed that S1 induced the translocation of SIRT3 from the nucleus to the mitochondria, which supports the findings of an earlier study (22). Because SIRT3 has been shown to serve as an important regulator of the balance between glycolytic and anabolic pathways and mitochondrial oxidative metabolism (15), we speculate that SIRT3 may be a key factor which participates in the regulation of both glucose metabolism and apoptosis induced by $\mathrm{S} 1$.

The function of SIRT3 varies in different normal and tumor tissues, and may be cell- and tumor-type specific (34). For example, combined with radiation and chemotherapy treatments, SIRT3 downregulation in OSCC cells further inhibited cell growth and increased cell death (35). Moreover, SIRT3 promotes cell survival of HT22 cells through attenuating oxidative stress induced by hydrogen peroxide and protecting mitochondrial function (36). In contrast, other reports indicate a proapoptotic function for SIRT3. SIRT3 was shown to induce growth arrest and apoptosis in several colorectal carcinoma and osteosarcoma cells, and in noncancer human cell lines such as retinal epithelial cells and lung fibroblasts (17).

As a novel antitumor target, the role of SIRT3 in ovarian cancer remains unclear. Here, we found that SIRT3 knockdown attenuated the apoptosis induced by S1, indicating that the activation of SIRT3 induced by S1 exerted a proapoptotic role in SKOV3 cells. In addition to regulating apoptosis, other studies have also shown that SIRT3 may regulate the activity of enzymes to coordinate global shifts in cellular metabolism (15). We found that SIRT3 knockdown effectively decreased the consumption of glucose and the production of lactate induced by S1 in SKOV3 cells. Furthermore, SIRT3 knockdown increased the expression of mitochondria-localized HK-II, a key glycolytic enzyme. Studies have shown that SIRT3-mediated dissociation of HK II from the mitochondria may activate apoptosis and inhibit glycolysis in some cancer cells $(23,37)$. These results indicated that SIRT3 activation is involved in the interruption of glucose metabolism and the induction of apoptosis induced by $\mathrm{S} 1$.

Tumor glycolysis is regarded as a target for cancer therapy (38), and experimental data show that the inhibition of glycolysis enhances cisplatin-induced apoptosis in ovarian cancer cells (39). Because our findings showed that earlier exposure 
to S1 mainly reduces mitochondrial respiration and that the upregulation of glycolysis seemed to be a compensatory effect, we speculated that the glycolysis inhibitor 2-DG would further aggravate the apoptosis induced by S1. Our study demonstrated that the inhibition of glycolysis may also enhance S1-induced apoptosis in ovarian cancer cells, with further upregulation of SIRT3. SIRT3 silencing partially reversed the effects of S1 on cell metabolism and apoptosis, while a combination of 2-DG and S1 further promoted the activation of apoptosis through enhancing the expression of SIRT3. In conclusion, our study shows that glycolysis should be considered a potential target for the improvement of S1 efficacy. Moreover, we show that SIRT3 is involved in both the glucose metabolism interruption and apoptosis induced by S1. Therefore, a novel strategy for tumor therapy could exploit the role of SIRT3 to enhance the antitumor effect of $\mathrm{BH} 3$ mimetics.

\section{Acknowledgements}

This study was supported by National Natural Science Foundation of China (nos. 81272876, 81472419 and 81541148) and the Foundation of Jilin Provincial Department of Health (no. 2013Z062).

\section{References}

1. Quinn BA, Dash R, Azab B, Sarkar S, Das SK, Kumar S, Oyesanya RA, Dasgupta S, Dent P, Grant S, et al: Targeting Mcl-1 for the therapy of cancer. Expert Opin Investig Drugs 20: 1397-1411, 2011.

2. Su J, Zhou L, Xia MH, Xu Y, Xiang XY and Sun LK: Bcl-2 family proteins are involved in the signal crosstalk between endoplasmic reticulum stress and mitochondrial dysfunction in tumor chemotherapy resistance. BioMed Res Int 2014: 234370 2014.

3. Hartman MŁ and Czyż M: BH3 mimetics as a strategy to complement anticancer therapies. Postepy Hig Med Dosw (Online) 66 67-77, 2012 (In Polish).

4. Giménez-Cassina A and Danial NN: Regulation of mitochondrial nutrient and energy metabolism by BCL-2 family proteins. Trends Endocrinol Metab 26: 165-175, 2015.

5. Chen ZX and Pervaiz S: Involvement of cytochrome $c$ oxidase subunits $\mathrm{Va}$ and $\mathrm{Vb}$ in the regulation of cancer cell metabolism by Bcl-2. Cell Death Differ 17: 408-420, 2010.

6. Lagadinou ED, Sach A, Callahan K, Rossi RM, Neering SJ, Minhajuddin M, Ashton JM, Pei S, Grose V, O'Dwyer KM, et al: BCL-2 inhibition targets oxidative phosphorylation and selectively eradicates quiescent human leukemia stem cells. Cell Stem Cell 12: 329-341, 2013.

7. Mérad-Saïdoune M, Boitier E, Nicole A, Marsac C, Martinou JC, Sola B, Sinet PM and Ceballos-Picot I: Overproduction of $\mathrm{Cu} / \mathrm{Zn}$-superoxide dismutase or $\mathrm{Bcl}-2$ prevents the brain mitochondrial respiratory dysfunction induced by glutathione depletion. Exp Neurol 158: 428-436, 1999.

8. Kueck A, Opipari AW Jr, Griffith KA, Tan L, Choi M, Huang J, Wahl H and Liu JR: Resveratrol inhibits glucose metabolism in human ovarian cancer cells. Gynecol Oncol 107: 450-457, 2007.

9. Muñoz-Pinedo C, El Mjiyad N and Ricci JE: Cancer metabolism: Current perspectives and future directions. Cell Death Dis 3: e248, 2012.

10. Deberardinis RJ, Sayed N, Ditsworth D and Thompson CB Brick by brick: Metabolism and tumor cell growth. Curr Opin Genet Dev 18: 54-61, 2008.

11. Andersen JL and Kornbluth S: The tangled circuitry of metabolism and apoptosis. Mol Cell 49: 399-410, 2013.

12. Green DR, Galluzzi L and Kroemer G: Cell biology. Metabolic control of cell death. Science 345: 1250256-1250256, 2014.

13. Suh DH, Kim MK, No JH, Chung HH and Song YS: Metabolic approaches to overcoming chemoresistance in ovarian cancer. Ann NY Acad Sci 1229: 53-60, 2011.
14. Kim HS, Patel K, Muldoon-Jacobs K, Bisht KS, Aykin-Burns N, Pennington JD, van der Meer R, Nguyen P, Savage J, Owens KM, et al: SIRT3 is a mitochondria-localized tumor suppressor required for maintenance of mitochondrial integrity and metabolism during stress. Cancer Cell 17: 41-52, 2010.

15. Finley LWS and Haigis MC: Metabolic regulation by SIRT3: Implications for tumorigenesis. Trends Mol Med 18: 516-523, 2012.

16. Bell EL, Emerling BM, Ricoult SJH and Guarente L: SirT3 suppresses hypoxia inducible factor $1 \alpha$ and tumor growth by inhibiting mitochondrial ROS production. Oncogene 30: 2986-2996, 2011.

17. Allison SJ and Milner J: SIRT3 is pro-apoptotic and participates in distinct basal apoptotic pathways. Cell Cycle 6: 2669-2677, 2007.

18. Zhong JT, Xu Y, Yi HW, Su J, Yu HM, Xiang XY, Li XN, Zhang $\mathrm{ZC}$ and Sun LK: The BH3 mimetic $\mathrm{S} 1$ induces autophagy through ER stress and disruption of Bcl-2/Beclin 1 interaction in human glioma U251 cells. Cancer Lett 323: 180-187, 2012.

19. Song T, Chang X, Zhang Z, Liu Y and Shen X: S1, a novel pan-BH3 mimetic, induces apoptosis in Mcl-1-overexpressing cells through Bak. J Pharmacol Sci 119: 330-340, 2012.

20. Bol V,Bol A,Bouzin C,Labar D,Lee JA, Janssens G, Porporato PE, Sonveaux P, Feron O and Grégoire V: Reprogramming of tumor metabolism by targeting mitochondria improves tumor response to irradiation. Acta Oncol 54: 266-274, 2015.

21. Giralt A and Villarroya F: SIRT3, a pivotal actor in mitochondrial functions: Metabolism, cell death and aging. Biochem J 444: 1-10, 2012.

22. Scher MB, Vaquero A and Reinberg D: SirT3 is a nuclear $\mathrm{NAD}^{+}$-dependent histone deacetylase that translocates to the mitochondria upon cellular stress. Genes Dev 21: 920-928, 2007.

23. Wei L, Zhou Y, Dai Q, Qiao C, Zhao L, Hui H, Lu N and Guo QL: Oroxylin A induces dissociation of hexokinase II from the mitochondria and inhibits glycolysis by SIRT3-mediated deacetylation of cyclophilin D in breast carcinoma. Cell Death Dis 4: e601, 2013.

24. Anderson AS, Roberts PC, Frisard MI, McMillan RP, Brown TJ, Lawless MH, Hulver MW and Schmelz EM: Metabolic changes during ovarian cancer progression as targets for sphingosine treatment. Exp Cell Res 319: 1431-1442, 2013.

25. Liu N, Xu Y, Sun JT, Su J, Xiang XY, Yi HW, Zhang ZC and Sun LK: The BH3 mimetic S1 induces endoplasmic reticulum stress-associated apoptosis in cisplatin-resistant human ovarian cancer cells although it activates autophagy. Oncol Rep 30: 2677-2684, 2013

26. Yi CH, Pan H, Seebacher J, Jang IH, Hyberts SG, Heffron GJ, Vander Heiden MG, Yang R, Li F, Locasale JW, et al: Metabolic regulation of protein $\mathrm{N}$-alpha-acetylation by Bcl-xL promotes cell survival. Cell 146: 607-620,2011.

27. Wensveen FM, Alves NL, Derks IAM, Reedquist KA and Eldering E: Apoptosis induced by overall metabolic stress converges on the Bcl-2 family proteins Noxa and Mcl-1. Apoptosis 16: 708-721, 2011.

28. Nishikawa T, Bellance N, Damm A, Bing H, Zhu Z, Handa K, Yovchev MI, Sehgal V, Moss TJ, Oertel M, et al: A switch in the source of ATP production and a loss in capacity to perform glycolysis are hallmarks of hepatocyte failure in advance liver disease. J Hepatol 60: 1203-1211, 2014.

29. Zhou Y, Tozzi F, Chen J, Fan F, Xia L, Wang J, Gao G, Zhang A, $\mathrm{Xia} \mathrm{X}$, Brasher $\mathrm{H}$, et al: Intracellular ATP levels are a pivotal determinant of chemoresistance in colon cancer cells. Cancer Res 72: 304-314, 2012.

30. Khwairakpam AD, ShyamanandaMS, SailoBL, RathnakaramSR, Padmavathi G, Kotoky J and Kunnumakkara AB: ATP citrate lyase (ACLY): A promising target for cancer prevention and treatment. Curr Drug Targets 16: 156-163, 2015.

31. Ganapathy-Kanniappan S and Geschwind J-FH: Tumor glycolysis as a target for cancer therapy: Progress and prospects. Mol Cancer 12: 152-152, 2013.

32. Sundaresan NR, Samant SA, Pillai VB, Rajamohan SB and Gupta MP: SIRT3 is a stress-responsive deacetylase in cardiomyocytes that protects cells from stress-mediated cell death by deacetylation of Ku70. Mol Cell Biol 28: 6384-6401, 2008.

33. Yang X, Xiang X, Xia M, Su J, Wu Y, Shen L, Xu Y and Sun L: Inhibition of JNK3 promotes apoptosis induced by BH3 mimetic S1 in chemoresistant human ovarian cancer cells. Anat Rec (Hoboken) 298: 386-395, 2015. 
34. Alhazzazi TY, Kamarajan P, Verdin E and Kapila YL: SIRT3 and cancer: Tumor promoter or suppressor? Biochim Biophys Acta 1816: 80-88, 2011.

35. Kamarajan P, Alhazzazi TY, Danciu T, D'silva NJ, Verdin E and Kapila YL: Receptor-interacting protein (RIP) and Sirtuin-3 (SIRT3) are on opposite sides of anoikis and tumorigenesis Cancer 118: 5800-5810, 2012.

36. Dai SH, Chen T, Wang YH, Zhu J, Luo P, Rao W, Yang YF, Fei $Z$ and Jiang XF: Sirt3 attenuates hydrogen peroxide-induced oxidative stress through the preservation of mitochondrial function in HT22 cells. Int J Mol Med 34: 1159-1168, 2014.
37. Shulga N, Wilson-Smith R and Pastorino JG: Sirtuin-3 deacetylation of cyclophilin D induces dissociation of hexokinase II from the mitochondria. J Cell Sci 123: 894-902, 2010.

38. Hamanaka RB and Chandel NS: Targeting glucose metabolism for cancer therapy. J Exp Med 209: 211-215, 2012.

39. Zhang L, Su J, Xie Q, Zeng L, Wang Y, Yi D, Yu Y, Liu S, Li S and $\mathrm{Xu}$ Y: 2-Deoxy-d-glucose sensitizes human ovarian cancer cells to cisplatin by increasing ER stress and decreasing ATP stores in acidic vesicles. J Biochem Mol Toxicol 29: 572-578, 2015. 